\title{
Tobacco Rattle Virus (TRV) based Virus-Induced Gene Silencing (VIGS) in Tomato (Solanum lycopersicum)
}

\author{
Gyan Prakash Srivastav, Shilpy Singh, Suniti, Vivek Rana and Pushpendra Kumar*
}

Department of Agricultural Biotechnology, Sardar Vallabhbhai Patel University of Agriculture and Technology, Meerut, U.P.-250110, India

*Corresponding author

\section{A B S T R A C T}

\section{Keywords}

Virus induced gene silencing,

Functional genomics, Silencing, TRV VIGS vector

\section{Article Info}

\section{Accepted:}

20 January 2021

Available Online:

10 February 2021
VIGS is a powerful tool for assaying the effects of gene silencing in plants. Efficient silencing requires the fragments that are more than $90 \%$ homologous to the target gene. Here, we designed a set of universal primers to a region of the PDS gene that is highly conserved among species, and therefore allows to isolate a fragment of the homologous PDS gene from the species of interest i.e., tomato. We typically use silencing of PDS which is used as a marker for gene silencing in tomatoes involved in carotene biosynthesis which results in a characteristic photobleaching phenotype in the leaves. The purpose of this study was to investigate the possibility of tomato PDS gene silencing, using VIGS technique by TRV based VIGS vector containing tomato PDS. The pTRV2: PDS vector carried inserts derived from tomato PDS gene was transformed into DH5a E. coli strain and then Agrobacterium tumefaciens GV3101 strain cells were transformed by the vectors containing PDS genes. The construct was validated for physical integrity as well as for biological functionality i.e., PDS by agroinfiltration method in the experimental host plant. The construct shows gene silencing results in photobleaching phenotype occurred in tomato plant leaves. However, plant infiltration with pTRV1 and pTRV2 (without PDS gene as control) mixed culture did not show any photobleaching. This construct found structurally as well as functionally active under plant system and can be further modified into transgene construct to be used to study the function of other genes through VIGS in tomato.

\section{Introduction}

Virus-induced gene silencing (VIGS) is a fast and efficient functional genomics tool (Becker and Lange, 2009; Baulcombe, 1999) and a method for rapid silencing of plant genes in order to discover their function (Becker and Lange, 2009; Purkayastha and Dasgupta, 2009). Virus- induced gene silencing (VIGS) offers an attractive and quick alternative for knocking out expression of a gene without the need to genetically transform the plant. VIGS 
is based on Post-Transcriptional Gene Silencing (PTGS), plants exploit PTGS as their innate antiviral defense line to encounter viral multiplication, employing defense mechanism very similar to the pathways of RNA interference which refers to interference in gene expression, mediated by small RNA in a sequence specific manner (Becker and Lange, 2009; Liu and Page, 2008).

At present many plant viruses are also being used to investigate plant genomic functions (Aguero et al., 2012; Hefferon, 2014; Lim et al., 2015; Wang et al., 2014). Impressive advances have also been made in the development of strategies for constructing viral vectors (Gleba et al., 2014), as well as viral vector delivery systems (Liu et al., 2002; Ryu et al., 2004; Seo et al., 2009; Tuttle et al., 2012; Yan et al., 2012).

VIGS vectors have been used to study gene function in plants, such as the potato virus $X$ (PVX) (Ruiz et al., 1998), tobacco rattle virus (TRV) is a bipartite, positive-strand RNA virus with theTRV1 and TRV2 genomes. TRV can infect meristem tissues whereas many other VIGS

vectors cannot (Ratcliff et al., 2001), and bean pod mottle virus (BPMV) (Zhang and Ghabrial, 2006). The VIGS system has been established in many types of plants, including $N$. benthamiana (Ratcliff et al., 2001), soybean (Zhang and Ghabrial, 2006), and potato (Brigneti et al., 2004). Many VIGS vectors have been described to study gene function in plants (Kumagai et al., 1995; Liu et al., 2002; Ratcliff et al., 2001; Ruiz et al., 1998). Most of these vectors are designed to work in Nicotiana benthamiana. Tomato is an economically important crop and like $N$. benthamiana, it belongs to the Solanaceous family. Nicotiana benthamiana was the first plant species for which VIGS was reported. The PDS gene of $N$. benthamiana was silenced by using a vector composed of hybrid sequences of both TMV and Tomato mosaic virus (ToMV) which resulted in extensive photo bleaching (Kumagai et al., 1995). Vectors using VIGS were applied for Agrobacterium tumefaciens mediated plant transformation, contained host genes inserted in the viral infection clone. Agrobacterium based inoculation was used for excision of TDNA containing the viral genome (Becker and Lange, 2009; Waterhouse and Helliwell, 2003) which was transcribed by the host's RNA polymerase.

The RNA-dependent RNA polymerase generates dsRNA, using ssRNA viral transcripts (Becker and Lange, 2009). This dsRNA is recognized by Dicer- like proteins and cleaved into small interfering RNAs (siRNAs) which are approximately 21- 24 nucleotides (nt) in length (Becker and Lange, 2009; Bernstein et al., 2001; Bass, 2000). The siRNAs are selected by RISC (RNA-induced Silencing Complex) and melted into ssRNAs which are used to target mRNAs and generate new siRNA (Becker and Lange, 2009; Agrawal et al., 2003). In this case the VIGS viral RNAs and the mRNA of the target geneare cleaved.

The single stranded siRNAs are generated (Becker and Lange, 2009; Lipardi et al., 2001) and spread as silencing signals throughout the plant resulting in systemic gene silencing distant from the site of infection and lead to leaf photobleaching (Becker and Lange, 2009).

In the present study, the gene for phytoene desaturase (PDS) was isolated and cloned from Solanum lycopersicum plant and used as VIGS reporter genes. Here, we were also used to establish a TRV-mediated VIGS system and optimize Agrobacterium-infiltration method in $S$. lycopersicum. This study shows that TRVmediated VIGS technology and tomato genomic sequences can be used in future 
studies that focus on gene function in $S$. lycopersicum.

\section{Materials and Methods}

\section{Plant Material}

Tomato seeds were collected from Department of Horticulture, College of Agriculture, SVPUA\&T Meerut. Seedlings of a tomato (Solanum lycopersicum) species were grown at approximately $20-25^{\circ} \mathrm{C}$. Tomato plants were raised in the field laboratory of Department of Agriculture Biotechnology of SVPUA\&T.

\section{Data mining and designing of degenerate PDS gene specific primer}

The publicly available gene sequence of tomato was searched for PDS gene from NCBI database (ftp://ftp.ncbi.nih.gov/blast/db/). The assembled sequences were searched for identification and localization of forward and reverse primers from the flanking sequences. The primers were designed using online available software.

\section{Isolation and cloning of the PDS cDNA from tomato}

Total RNA was isolated from leaves of tomato using Gene JET Plant RNA Purification Mini Kit (Thermo Scientific). The reaction mixtures for cDNA synthesis were prepared using cDNA direct TMkit (GeNeiTM, Bangalore).

The PDS gene was obtained by PCR amplification from a tomato leaves cDNA using PDS gene-specific primers (forward primer: 5'-CGGGAATTCGGC(A/T) CT $(C / T) A A C T T(C / T) A T A A A(C / T) C \quad-3^{\prime}$; reverse primer:5'-CGGTCTAGATCAGTTT (T/C)CTGTCAAACC -3'). The PCR amplification was carried out using with the following cycling parameters: heating for 3 min at $94^{\circ} \mathrm{C}$, total 40 cycles of denaturation at $95^{\circ} \mathrm{C}$ for $1 \mathrm{~min}$, annealing for $30 \mathrm{~s}$ at $59^{\circ} \mathrm{C}$, synthesis for $1 \mathrm{~min}$ at $72^{\circ} \mathrm{C}$ and extension at $72^{\circ} \mathrm{C}$ for $10 \mathrm{~min}$. The gene fragment of around 406 bp was obtained and cloned into the pGEM-T Easy vector (Promega), and confirmed by sequencing.

Two clones of PDS gene were sequenced in both the directions (with SP6 and T7 universal primers). The sequencing was carried out at the DNA sequencing facility, Eurofins Genomics.

The nucleotide sequences were subjected to BLAST analysis (http://www.ncbi.nlm.nih. gov/blast/) to confirm the sequences thus generated are of tomato genome. Sequences generated were trimmed and assembled manually to retain only the coding regions of each gene by removing vector sequences as well as the nucleotide sequences flanking the protein coding regions.

The fragment obtained after trimming was somewhat similar to some of the PDS ortholog. The nucleotide sequence reported in this paper has been submitted to GenBank under the accession number: PDS, MN044575.

The phylogenetic tree was constructed with the Neighbor-Joining algorithm using the software MEGA 7.0(http://www.megasoftware.net/).

The PDS cDNA fragment was excised using EcoRI and XbaI digestion from the pGEM-T: PDS plasmid, then subcloned into pTRV2 to generate a pTRV2:PDS construct.

\section{Computer software and programs used}

\section{Homology study}

Multiple sequence alignment was performed by CLUSTAL-W program in BioEdit software version 5.0.9 (Tom Hall, Raleigh, NC, USA) (Hall, 1999). 


\section{Phylogenetic analysis}

Mega program version 7 (Kumar et al., 2016) use for the construction of phylogenetic tree of various orthologous sequences of PDS genes.

\section{Agro-infiltration}

According to the described method by Velasquez et al., 2009 for each experiment, $A$. tumefaciens harboring pTRV1, pTRV2 and pTRV2: tPDS were grown on LB plates supplemented with $50 \mu \mathrm{g} / \mathrm{ml}$ of kanamycin. Three ml liquid culture of LB containing mentioned antibiotics was inoculated with each of the strains and incubated in a shaker at $30^{\circ} \mathrm{C}$ for 18 hours. A 1: 25 dilution of the culture was inoculated into liquid induction media (IM) with kanamycin and $200 \mu \mathrm{M}$ acetosyringone. The cells were harvested by centrifugation for 10 minutes at $3000 \mathrm{rpm}$ and were resuspend with $10 \mathrm{mM} \mathrm{MgCl} 2,10 \mathrm{mM}$ MES $\mathrm{pH}$ 5.5. Acetosyringone was added to a final concentration of $400 \mu \mathrm{M}$ to pTRV1 culture. Cultures containing the pTRV1, pTRV2, and pTRV2: tPDS were mixed in a 1:1 ratio. Using $1 \mathrm{ml}$ syringe, mixed cultures were infiltrated into the lower leaves of 2-week-old tomato plants.

\section{RT-PCR Analysis}

Total RNA was extracted from $100 \mathrm{mg}$ fresh green and white tomato tissue samples (Fig.4.8) using GeneJET Plant RNA Purification Mini Kit (Thermo Scientific, \#K0801, \#K0802) and treated with RNase-free DNase (Ambion) to remove any contaminating genomic DNA. The first strand cDNA was synthesized using $2 \mu \mathrm{g}$ total RNA for cDNA synthesis were prepared using cDNA direct ${ }^{\mathrm{TM}}$ kit $\left(\mathrm{GeNei}^{\mathrm{TM}}\right.$, Bangalore). The primers for amplifying PDS transcripts by quantitative PCR were designed outside the region targeted for gene silencing to avoid amplification from the pTRV:PDS construct. These primers were 5'- CTTTGCAAGCCAATTGTTGA-3' and5'TTGTAGGGGTCGACATGGTT-3'.

\section{Results and Discussion}

\section{Design of primers to amplify PDS gene fragments}

A BLAST search for PDS sequences from a wide range of taxa permitted us to design a set of degenerate primers that would amplify a PDS fragment from known species, and therefore, most probably from species where the gene's sequence is unknown. An approximately 406bp fragment of the PDS gene was amplified by the degenerate primers from tomato species. A comparison of the PDS fragment sequences from 4 different plant species reveals a similarity of higher than $80 \%$ but in most cases less than the $90 \%$ homology required for efficient VIGS. It seems likely that most other species will include the highly conserved region of the PDS gene amplified by this pair of degenerate primers (Fig.1).

\section{PDS gene isolation, cloning and sequencing}

The PDS gene was isolated from the cDNA of leaves samples of tomato. PCR was carried out using PDS gene specific primer for amplification of PDS gene. A coding region of around $406 \mathrm{bp}$ was amplified and visualized in the 1\% Agarose gel electrophoresis (Fig. 2). The PCR product of PDS gene was eluted and cloned in pGEMT cloning vector, and several transformed clones were confirmed by blue white screening.

Thereafter by colony PCR(Fig.3) as recombinant clones using the PDS gene specific primer following standard protocol (Sambrook and Russell, 2001). After colony PCR, the colony showing positive result was used for Plasmid isolation and Restriction digestion of the plasmid with EcoRI and XbaI sites to confirm that the plasmid contained the PDS gene (Fig. 4). After confirmation of recombinant clones, two clones were sequenced using the vector derived primer in automatic sequencer and presented in Fig.5. 
Multiple sequence alignment and phylogenetic analysis of isolated PDS gene with PDS genes of other species

Multiple sequence alignment of amino acid sequence of isolated PDS gene from tomato with other orthologous PDS gene of other species including Petunia hybrida, Gladiolus hybrida, Arabidopsis thaliana, Oryza sativa and Nicotiana tabacum along with their Accession numbers gene of other species to find out the changes in amino acid sequence performed by CLUSTAL-W program in BioEdit software version 5.0.9 (Tom Hall, Raleigh, NC, USA) (Hall, 1999) (Fig. 6).

The phylogenetic study of PDS amino acid sequences were analysed in present study using Mega program version 7 (Kumar et al., 2016). The bootstrap values of the phylogenetic trees were derived from 1000 replicates run. According to amino acid-based NeighborJoining tree analysis the PDS gene which we isolate from tomato varieties in this study is matched with AKM12416.1 Petunia hybrida (Fig.7).

\section{Construct Development}

As a result of PCR amplification of PDS insert (406bp) by using specific primer (PDS-F and PDS-R). The insert thus generated was cloned successfully in pGEMT Easy cloning vector (clone was named as pGEMT:PDS). The recombinant colonies yielded the amplicon of expected size when subjected to colony PCR. The plasmid from the colony PCR positive recombinant colonies released the insert of expected size in restriction digestion analysis (Fig. 4). Sequencing of this clone yielded an insert containing 406nt (6 bp of restriction enzyme sites in both primers and $3 \mathrm{bp}$ additional nucleotide on 5 ' end of $\mathrm{F} \& \mathrm{R}$ primers) than the actual size of template i.e 424bp.The gel purified product released from size from pGEMT: PDS clone was sub-cloned successfully at EcoRI and XbaI sites through directional cloning in the MCS of pTRV2 (pYL156). This yielded several colonies after transformation in DH5 $\alpha$ and recovered recombinant colonies based on colony PCR (Fig. 8). This transgene insert was found to be cloned successfully intopTRV2.

Mobilization of transgene constructs into Agrobacterium tumefaciens

The construct was mobilized into the chemically competent cells of Agrobacterium tumefaciensstrainGV3101 by freeze and thaw shock transformation method and obtained recombinant colonies. Agrobacterium colonies harboring transgene construct was confirmed by colony PCR using insert specific primers to amplify the transgene of construct and obtained the amplicon of expected size (Fig.9).

\section{AgroInfiltration}

A colony PCR confirmed clone of transgene construct (pTRV2: PDS) was used in transient expression assay in tomato plant (Solanum lycopersicon) through syringe (without needle) infiltration. After 15-20 days, the infiltrated leaf tissues were subjected to PDS expression assay (Fig.10).

TRV-mediated VIGS in Solanum lycopersicum

In order to investigate whether the TRV vectors can directly infect tomato leaves, a mixture of Agrobacterium cultures containing pTRV1 (pYL192) and pTRV2 (pYL156) constructs in a 1:1 ratio was infiltrated into few leaves of two-week-old tomato plant. The seedlings infected were grown at $22^{\circ} \mathrm{C}$. Four weeks after agroinfiltration, more than twenty plants inoculated with TRV1 and TRV2 vectors showed no obvious differences in overall shoot and leaf morphology compared with the control (Fig.10). 


\section{Silencing of the tomato PDS gene using TRV-VIGS vector}

We tested whether the TRV clones could induce gene silencing in tomato plants. In order to do so, we examined the ability of our TRV-VIGS vector to suppress the expression of the endogenous phytoene desaturase gene (PDS) in Pusa Ruby and NDT-7 variety of tomato. A mixture of Agrobacterium cultures containing pTRV2, carrying tomato PDS (pTRV2: tPDS), and pTRV1, was infiltrated onto the lower leaves of 2-week-old tomato plants (Fig.4.8). Tomato plants infected with pTRV-tPDS developed a photo-bleached phenotype in the upper leaves 15-20 days post Agro-infiltration and remained white for at least 1 month. The Agrobacterium infiltration method of infecting pTRV:tPDS resulted in $60 \%$ and $40 \%$ PDS silencing phenotype in Pusa Ruby and NDT-7 varieties of tomato respectively i.e. three out of ten plants in Pusa Ruby and two out of ten plants in NDT-7 tomato varieties (Table No.4.1). Fragments isolated from the target species using our universal primers were very effective when used in VIGS silencing of PDS. Developing leaves of pTRV2-PDS infected plants showed the photobleaching phenotype that indicated movement of the virus and its effectiveness in silencing the native PDS gene in tomato. No photo-bleached phenotype was found in the control or pTRV2 empty vector controls (Fig.10).

\section{Expression analysis of PDS gene}

To confirm gene silencing at the molecular level, we performed quantitative RT-PCR analyses to quantify the transcript levels of the silenced endogenous genes. Gene-specific primers for tPDS were used to amplify the respective genes. After amplification, PDS gene transcripts were clearly evident in non- silenced leaves and vector control, but barely detected in photo-bleaching leaves. The result suggested that the photo-bleaching phenotype was caused by the down-regulation of the PDS gene (Fig. 11). These findings reveal the potential for functional characterization of genes expressed in leaves that are involved in diverse biological functions (physiological, biochemical, and plant-microbe interactions).

Virus-induced gene silencing is an excellent functional genomics tool for gene function analyses (Liu et al., 2002; Robertson, 2004; Lange et al., 2013). In previous VIGS studies of a wide range of different ornamentals (Chen et al., 2003), only $N$. benthamiana and $P$. hybrida (both from the Solanaceae) showed the PDS phenotype. PDS silencing in $N$. benthamiana inhibits carotenoid biosynthesis, causing the plants to exhibit a photo-bleached phenotype (Kumagi et al., 1995; Burch-Smith et al., 2004; Howes, 2005; Goodin et al., 2008). PDS gene which encodes the important enzymes in the carotenoid biosynthesis pathway was targeted. PDS silencing is an indicator for gene silencing and shows a clear mutant phenotype (Lu et al., 2003). We used TRV [bipartite RNA virus; TRV-RNA1 (TRV1) and TRV-RNA2 (TRV2)] as a VIGS vector. This virus has already been used for VIGS in many plants, including dicots and monocots (Ratcliff et al., 2001; Burch-Smith et al., 2004; Brigneti et al., 2004; Becker and Lange, 2010) and recently in potato (Brigneti et al., 2004). Ye et al., (2009) reported that TRV-based vector could trigger virus-induced gene silencing in Jatropha curcas L., which is a small tropical, woody tree belonging to the Euphorbiaceae family. Recently, an Agrobacterium-mediated VIGS assay was successfully developed in several cotton cultivars with various genetic backgrounds (Gao et al., 2011). 
Table.1 Phenotypic efficiency showed in green tissues plant and white tissues plant (PDS silenced)

\begin{tabular}{|c|c|c|c|c|}
\hline S.No. & Variety & Treatment & $\begin{array}{l}\text { Green tissues plant } \\
\qquad(\%)\end{array}$ & $\begin{array}{l}\text { White tissues } \\
\text { plant (PDS } \\
\text { Silenced \%) }\end{array}$ \\
\hline \multirow[t]{2}{*}{1} & \multirow{2}{*}{$\begin{array}{l}\text { Pusa } \\
\text { Ruby }\end{array}$} & Control & $100 \%$ & Nil* \\
\hline & & $\begin{array}{l}\text { Agroinoculation } \\
\text { With pTRV- } \\
\text { tPDS }\end{array}$ & $40 \%$ & $60 \%$ \\
\hline \multirow[t]{2}{*}{2} & \multirow[t]{2}{*}{ NDT-7 } & Control & $100 \%$ & Nil* \\
\hline & & $\begin{array}{c}\text { Agroinoculation } \\
\text { With pTRV- } \\
\text { tPDS }\end{array}$ & $60 \%$ & $40 \%$ \\
\hline
\end{tabular}

*Nil indicates the no photo-bleacedphynotipic expresion.

Fig.1 Multiple sequence alignment and sequence comparison of the PDS fragments from the four different plants for designing of degenerate primers

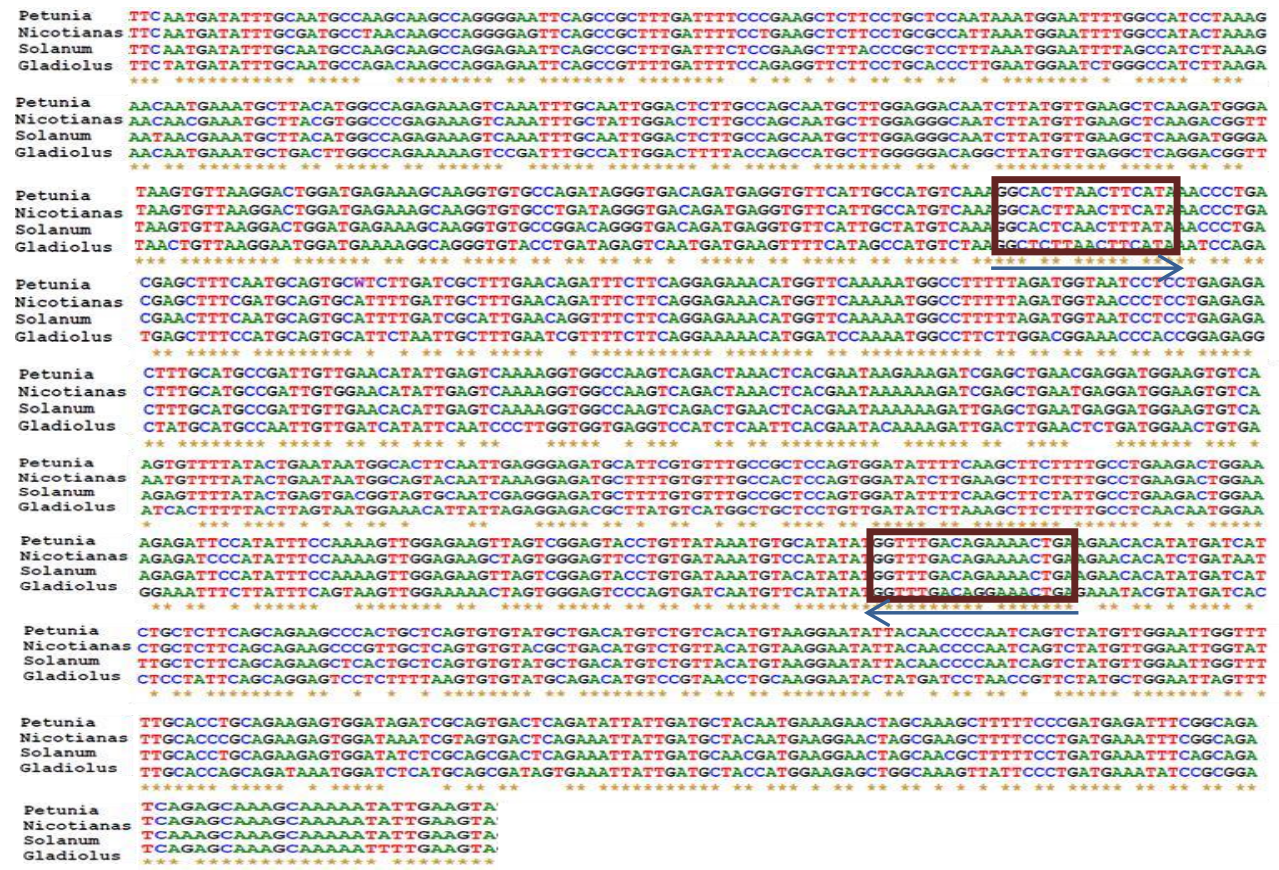


Fig.2 PDS gene fragments were amplified by the universal primers from tomato varieties. The size of the PDS fragment is approximately $406 \mathrm{bp}$. Lane 1: amplification of PDS gene from Pusa Ruby variety. Lane; M: 100bp DNA Ladder, GeneRuler (Fermentas); Lane 2: amplification of PDS from NDT-7variety

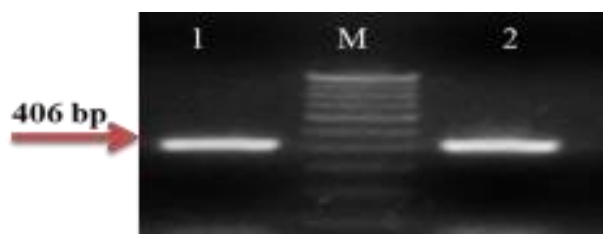

Fig.3 Colony PCR for PDS amplification from pGEMT vector transformed in DH5 $\alpha$ cells. Lane M: 100bp DNA Ladder, GeneRuler (Fermentas); Lane 1-4: four colonies grown on antibiotic media.

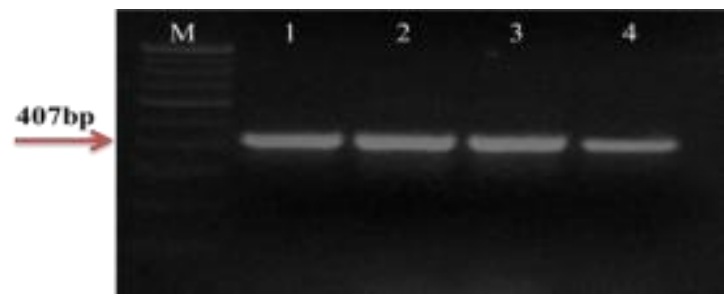

Fig.4 Restriction Digestion of PDS and TRV2 vector with EcoRI\&XbaI: Lane M: 1Kb DNA Ladder, GeneRuler (Fermentas); Lane 1-3: Restriction release of PDS from pGEMT cloning vector; Lane 4-6: Restriction of TRV2

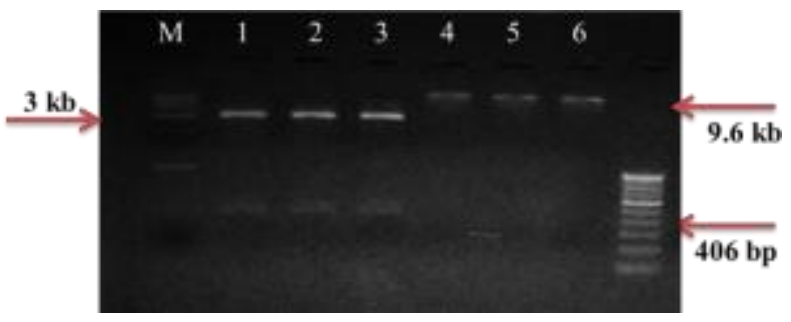

Nucleotide and amino acid sequence 
Fig.5 PDS gene nucleotide and amino acid sequence after Sequencing

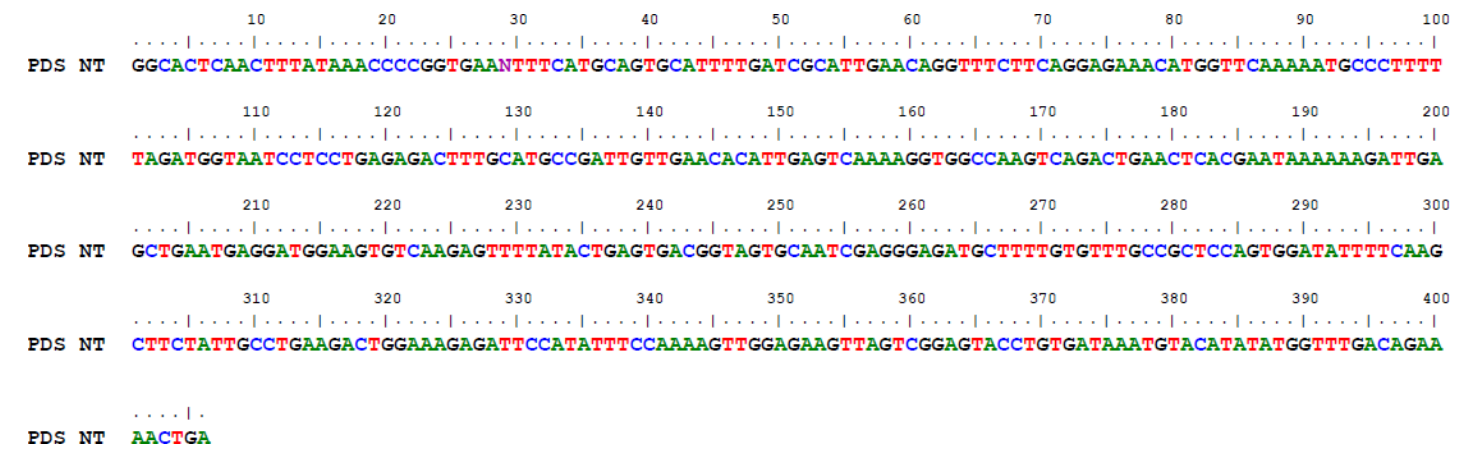

\section{Amino acid sequence}

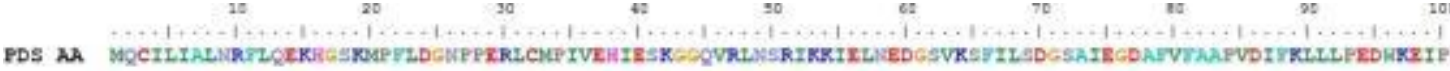

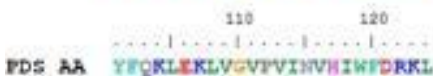

Fig.6 Multiple sequence alignment of amino acid sequences of PDS gene and PDS gene from tomato, Petunia, Gladiolus, Arabidopsis and other species to identify the conserved region among these species performed by Clustal W program using BioEdit software version 5.0.9.

$\operatorname{PDS} \mathrm{AL}$

AGI17588.1 Gladiolus hybrida ARDO2489.1 Oryza sativa aru12416.1 Petunia hybrida MP 001234095.1 Solantur lyeoper N 001329033.1 Arabidopsis tha CAË83576.1 Nicotiana tabacun Clustal Consensus

PDS AR

NGI17588.1 Gladiolus hybrida NoD2489.1 Oryza sativa AFU12416.1 Petunia hybrida IIP 001234095.1 Solanum lycoper No 001329033.1 Arabidopgis tha CAËB3576.1 Nicotiana tabacun Clustal Consensus

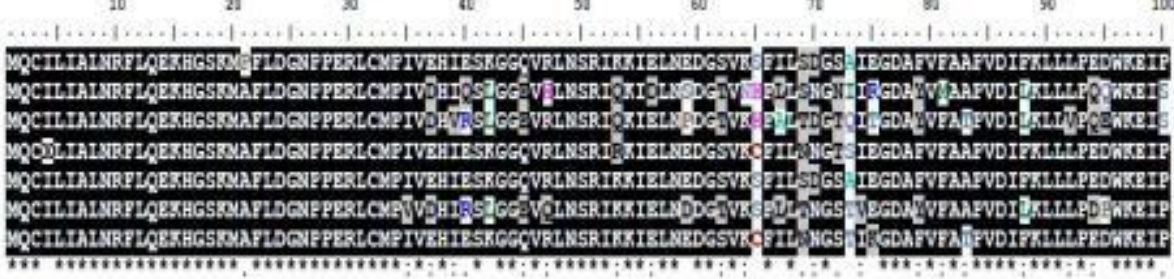

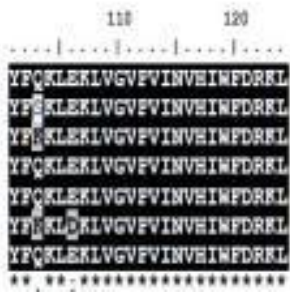


Fig.7 Neighbor-joining tree of PDS genes from tomato, Petunia, Arabidopsis and other species. 100 bootstrap samples were generated to assess support for the informed relationship. Local bootstrap probabilities (\%) are indicated near the branching points using the Mega 7 software

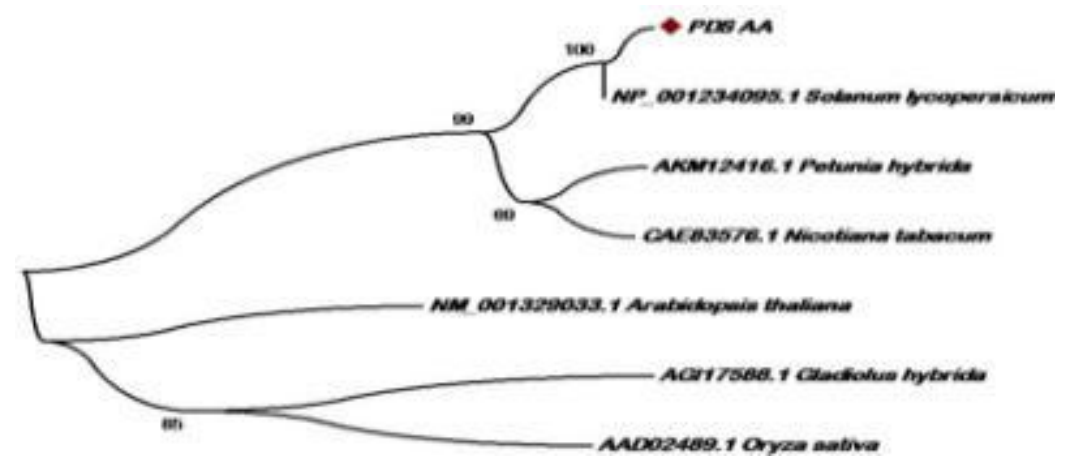

Fig.8 Colony PCR amplification of PDS from TRV2, vector transformed in DH5 $\alpha$ cells. Lane M: 100 bp DNA Ladder, GeneRuler (Fermentas); Lane 1-3: three colonies grown on antibiotic media; Lane 4: Negative control; Lane 5: Positive Control.

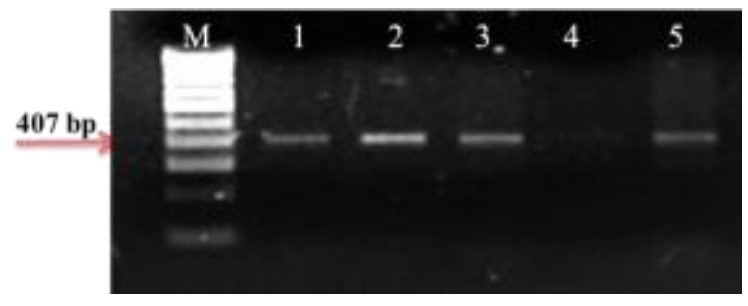

Fig.9 Colony PCR amplification of PDS from recombinant TRV2 vector transformed in GV3101 cells; Lane M: 100 bp DNA Ladder, GeneRuler (Fermentas); Lane 1-4: four colonies grown on antibiotic media; Lane 5: Positivecontrol

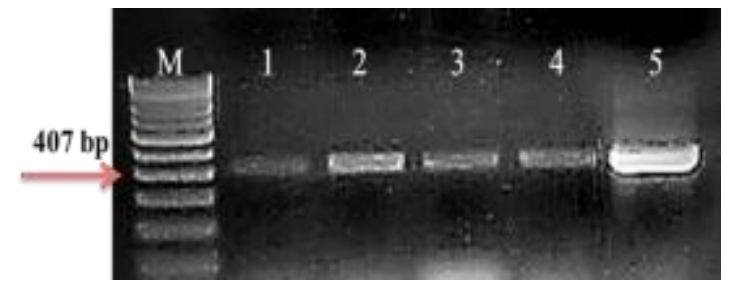


Fig.10 A and B; Photobleaching phenotype resulting from VIGS silencing of TRV:tPDS gene in Pusa Ruby and NDT-7 plant variety respectively. C; control plant and D; TRV infected plant.
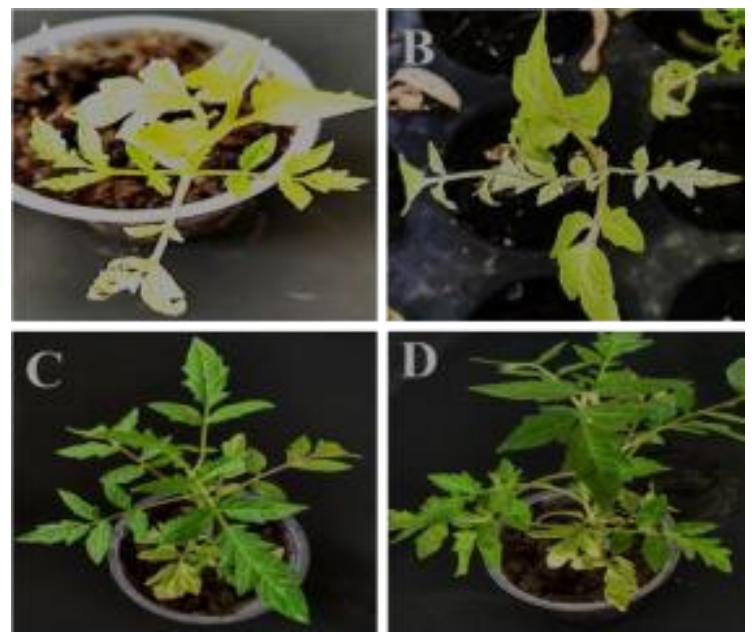

Fig.11 Abundance of PDS transcripts in tomato plants after VIGS silencing. S-silenced tissue, NS- non-silenced tissue, E-empty vector control

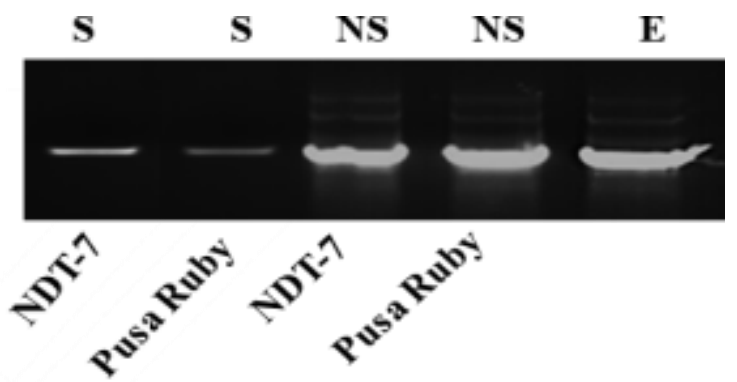

This method will be useful for functional analysis of many genes interest of tomato and will fulfill its promise of being a fast and efficient functional genomicstool.

Virus-induced gene silencing is an excellent functional genomics tool for gene function analyses. Agro infiltration is a novel and simple method to elicit VIGS with greater rapidity and convenience, whole-plant level gene silencing, adequately stable transformation and suitability for studying functions of genes involved in seed germination and early plant development stages. The ease of the agroinfiltration method suggests it would be a better choice for high throughput gene silencing. Agroinfiltration method can be used for efficient VIGS in various Solanaceae species. We have demonstrated that agroinfiltration shuts down transcript levels to a greater degree in leaves. This may allow us to do gene functional analysis.

\section{Acknowledgement}

We are thankful to the Department of Agricultural Biotechnology, College of Agriculture, SVPUA\&T, Meerut for providing necessary facilities.

\section{Funding}

No substantial funding to be stated. 


\section{References}

Agrawal, N., Dasaradhi, P. V. N., Mohmmed, A., Malhotra, P., Bhatnagar, R. K. and Mukherjee, S. K. (2003). RNA interference: biology, mechanism, and applications. Microbiol. Mol. Biol. Rev., 67(4), 657-685.

Agüero, J., Ruiz-Ruiz, S., del Carmen Vives, M., Velázquez, K., Navarro, L., Peña, L. and Guerri, J. (2012). Development of viral vectors based on Citrus leaf blotch virus to express foreign proteins or analyze gene function in citrus plants. Molecular plant- microbe interactions, 25(10), 1326-1337.

Bass, B. L. (2000). Double-stranded RNA as a template for gene silencing. Cell, 101(3), 235-238.

Baulcombe, D. C. (1999). Fast forward genetics based on virus-induced gene silencing. Current opinion in plant biology, 2(2), 109-113.

Becker, A. and Lange, M. (2010). VIGSgenomics goes functional. Trends in plant science, 15(1),1-4.

Bernstein, E., Caudy, A. A., Hammond, S. M. and Hannon, G. J. (2001). Role for a bidentate ribonuclease in the initiation step of RNA interference. Nature, 409(6818), 363.

Brigneti, G., Martín-Hernández, A. M., Jin, H., Chen, J., Baulcombe, D. C., Baker, B. and Jones, J. D. (2004). Virus-induced gene silencing in Solanum species. The Plant Journal, 39(2), 264-272.

Brigneti, G., Voinnet, O., Li, W. X., Ji, L. H., Ding, S. W. and Baulcombe, D. C. (1998). Retracted: Viral pathogenicity determinants are suppressors of transgene silencing in Nicotiana benthamiana. The EMBO journal, 17(22),6739-6746.

Burch-Smith, T. M., Anderson, J. C., Martin, G. B. and Dinesh-Kumar, S. P. (2004). Applications and advantages of virus-induced gene silencing for gene function studies in plants. The Plant Journal, 39(5), 734-746.

Chen, J. C., Johnson, F., Clark, D. G., Gookin, T. and Reid, M. S. (2003, August). Potential application of virus-induced gene silencing (VIGS) in flower senescence studies. In VIII International Symposium on Postharvest Physiology of Ornamental Plants 669 (pp.147-152).

Gao, X., Wheeler, T., Li, Z., Kenerley, C. M., He, P. and Shan, L. (2011). Silencing GhNDR1 and GhMKK2 compromises cotton resistance to Verticillium wilt. The Plant Journal, 66(2), 293-305.

Gleba, Y. Y., Tusé, D. and Giritch, A. (2013). Plant viral vectors for delivery by Agrobacterium. In Plant viral vectors (pp. 155-192). Springer, Berlin, Heidelberg.

Hall, T. A. (1999, January). BioEdit: a userfriendly biological sequence alignment editor and analysis program for Windows 95/98/NT. In Nucleic acids symposium series (Vol. 41, No. 41, pp. 95-98). [London]: Information Retrieval Ltd.,c1979-c2000.

Hefferon, K. (2014). Plant virus expression vector development: new perspectives. BioMed research international,2014.

Howes, T. and Kumagai, M. H. (2005). Virusinduced gene silencing in Nicotiana benthamiana using a DEAD-box helicase sequence derived from Dunaliella salina. The Journal of Young Investigators, 12.

Kumagai, M. H., Donson, J., Della-Cioppa, G., Harvey, D., Hanley, K. and Grill, L. K. (1995). Cytoplasmic inhibition of carotenoid biosynthesis with virusderived RNA. Proceedings of the National Academy of Sciences, 92(5),1679-1683.

Kumar, S., Stecher, G. and Tamura, K. (2016). MEGA7: molecular evolutionary 
genetics analysis version 7.0 for bigger datasets. Molecular biology and evolution, 33(7), 1870- 1874.

Lange, M., Yellina, A. L., Orashakova, S. and Becker, A. (2013). Virus-induced gene silencing (VIGS) in plants: an overview of target species and the virus-derived vector systems. In Virus-Induced Gene Silencing (pp. 1-14). Humana Press, Totowa, NJ.

Lim, S., Nam, M., Kim, K. H., Lee, S. H., Moon, J. K., Lim, H. S. and Moon, J. S. (2016). Development of a new vector using Soybean yellow common mosaic virus for gene function study or heterologous protein expression in soybeans. Journal of Virological Methods, 228,1-9.

Lipardi, C., Wei, Q. and Paterson, B. M. (2001). RNAi as random degradative PCR: siRNA primers convert mRNA into dsRNAs that are degraded to generate new siRNAs. Cell, 107(3),297-307.

Liu, E. and Page, J. E. (2008). Optimized cDNA libraries for virus-induced gene silencing (VIGS) using tobacco rattle virus. Plant methods, 4(1),5.

Liu, Y., Schiff, M. and Dinesh-Kumar, S. P. (2002). Virus-induced gene silencing in tomato. The Plant Journal, 31(6), 777786.

Lu, R., Martin-Hernandez, A. M., Peart, J. R., Malcuit, I. and Baulcombe, D. C. (2003). Virus-induced gene silencing in plants. Methods, 30(4), 296-303.

Maillard, P. V., Ciaudo, C., Marchais, A., Li, Y., Jay, F., Ding, S. W. and Voinnet, O. (2013). Antiviral RNA interference in mammalian cells. Science, 342(6155), 235-238.

Purkayastha, A. and Dasgupta, I. (2009). Virus-induced gene silencing: a versatile tool for discovery of gene functions in plants. Plant Physiology and Biochemistry, 47(11-12), 967-976.
Ratcliff, F., Martin-Hernandez, A. M. and Baulcombe, D. C. (2001). Technical advance: tobacco rattle virus as a vector for analysis of gene function by silencing. The Plant Journal, 25(2), 237-245.

Ratcliff, F., Martin-Hernandez, A. M. and Baulcombe, D. C. (2001). Technical advance: tobacco rattle virus as a vector for analysis of gene function by silencing. The Plant Journal, 25(2), 237-245.

Robertson, D. (2004). VIGS vectors for gene silencing: many targets, many tools. Annu. Rev. Plant Biol., 55,495-519.

Ryu, C. M., Anand, A., Kang, L. and Mysore, K. S. (2004). Agrodrench: a novel and effective agroinoculation method for virus-induced gene silencing in roots and diverse Solanaceous species. The Plant Journal, 40(2), 322-331.

Seo, J. K., Lee, H. G. and Kim, K. H. (2009). Systemic gene delivery into soybean by simple rub-inoculation with plasmid DNA of a Soybean mosaic virus-based vector. Archives of virology, 154(1),87.

Tuttle, J. R., Haigler, C. H. and Robertson, D. (2012). Method: low-cost delivery of the cotton leaf crumple virus-induced gene silencing system. Plant methods, $8(1), 27$.

Velásquez, A. C., Chakravarthy, S. and Martin, G. B. (2009). Virus-induced gene silencing (VIGS) in Nicotiana benthamiana and tomato. JoVE(Journal of Visualized Experiments), (28),e1292.

Wang, Y., Cong, Q. Q., Lan, Y. F., Geng, C., $\mathrm{Li}, \mathrm{X}$. D., Liang, Y. C. and Li, X. D. (2014). Development of new potato virus $\mathrm{X}$-based vectors for gene overexpression and gene silencing assay. Virus research, 191,62-69.

Waterhouse, P. M. and Helliwell, C. A. (2003). Exploring plant genomes by RNAinduced gene silencing. Nature Reviews Genetics, 4(1),29. 
Welsch, R., Beyer, P., Hugueney, P., Kleinig, H. andvon Lintig, J. (2000). Regulation and activation of phytoene synthase, a key enzyme in carotenoid biosynthesis, during photomorphogenesis. Planta, 211(6), 846-854.

Yan, H. X., Fu, D. Q., Zhu, B. Z., Liu, H. P., Shen, X. Y. and Luo, Y. B. (2012). Sprout vacuum-infiltration: a simple and efficient agroinoculation method for virus-induced gene silencing in diverse solanaceous species. Plant cell reports, 31(9),1713-1722.

Ye, J., Qu, J., Bui, H. T. N. and Chua, N. H. (2009). Rapid analysis of Jatropha curcas gene functions by virus-induced gene silencing. Plant biotechnology journal, 7(9), 964- 976.

\section{How to cite this article:}

Gyan Prakash Srivastav, Shilpy Singh, Suniti, Vivek Rana and Pushpendra Kumar. 2021. Tobacco Rattle Virus (TRV) based Virus-Induced Gene Silencing (VIGS) in Tomato (Solanum lycopersicum). Int.J.Curr.Microbiol.App.Sci. 10(02): 2731-2744.

doi: https://doi.org/10.20546/ijcmas.2021.1002.302 